\title{
Oxalic acid production by Aspergillus niger: an oxalate-non-producing mutant produces citric acid at pH 5 and in the presence of manganese
}

\author{
George J. G. Ruijter, Peter J. I. van de Vondervoort and Jaap Visser
}

Author for correspondence: Jaap Visser. Tel: +31317 484439. Fax: +31 317484011. e-mail: office@algemeen.mgim.wau.nl

Section Molecular Genetics of Industrial Microorganisms, Wageningen Agricultural University, Dreijenlaan 2, $6703 \mathrm{HA}$ Wageningen, The Netherlands
The external $\mathrm{pH}$ appeared to be the main factor governing oxalic acid production by Aspergillus niger. A glucose-oxidase-negative mutant produced substantial amounts of oxalic acid as long as the $\mathrm{pH}$ of the culture was 3 or higher. When $\mathrm{pH}$ was decreased below 2 , no oxalic acid was formed. The activity of oxaloacetate acetylhydrolase (OAH), the enzyme believed to be responsible for oxalate formation in $A$. niger, correlated with oxalate production. OAH was purified from $A$. niger and characterized. OAH cleaves oxaloacetate to oxalate and acetate, but $A$. niger never accumulated any acetate in the culture broth. Since an $A$. niger acuA mutant, which lacks acetylCoA synthase, did produce some acetate, wild-type $A$. niger is apparently able to catabolize acetate sufficiently fast to prevent its production. An A. niger mutant, prtF28, previously isolated in a screen for strains deficient in extracellular protease expression, was shown here to be oxalate nonproducing. The prtF28 mutant lacked OAH, implying that OAH is the only enzyme involved in oxalate production in A. niger. In a traditional citric acid fermentation low $\mathrm{pH}$ and absence of $\mathrm{Mn}^{2+}$ are prerequisites. Remarkably, a strain lacking both glucose oxidase (goxC) and OAH (prtF) produced citric acid from sugar substrates in a regular synthetic medium at pH 5 and under these conditions production was completely insensitive to $\mathrm{Mn}^{2+}$.

Keywords: oxalic acid, citric acid, oxaloacetate acetylhydrolase, acetyl-CoA synthase, A. niger

\section{INTRODUCTION}

Oxalic acid is produced by a variety of fungi, including saprophytic and phytopathogenic species (excellently reviewed by Dutton \& Evans, 1996). In phytopathogenic fungi it is believed to play a role in pathogenesis, facilitating plant cell wall degradation. In saprophytic species, such as Aspergillus niger, the role of oxalic acid production is less clear, but may also be related to mobilizing substrates from plant cell wall polysaccharides, e.g. pectin (Tanaka \& Nonaka, 1981). Both through acidification and via its chelating properties oxalic acid may increase availability of metal ions such as iron and calcium (Dutton \& Evans, 1996). On the other hand, Murphy \& Levi (1983) have suggested that

Abbreviations: ACS, acetyl-COA synthase (EC 6.2.1.1); OAH, oxaloacetate acetylhydrolase (EC 3.7.1.1). formation of copper oxalate crystals resulted in a higher copper tolerance for several fungi, including A. niger. Alternatively, oxalic acid formation by A. niger may be involved in biological competition (Shanta \& Rati, 1990). The biosynthesis of oxalic acid seems to fit the general strategy of $A$. niger and other fungi to acidify their environment via an extracellular process involving glucose oxidase, by secreting organic acids which first accumulate intracellularly, or by a combination of these processes. A. niger is a very efficient oxalic acid producer, which can be illustrated by the findings of Van de Merbel et al. (1994), who reported production of $13 \mathrm{~g}$ oxalic acid $\mathrm{l}^{-1}$ from $20 \mathrm{~g}$ sugar $\mathrm{l}^{-1}$ in 45 h. Production of $38 \mathrm{~g}$ oxalic acid $\mathrm{l}^{-1}$, which is close to the solubility of sodium oxalate, was reported by Strasser et al. (1994) using a fed-batch process at $\mathrm{pH} 6$ with sucrose as the carbon source.

Several pathways have been described for oxalic acid 
production. In A. niger (Hayashi et al., 1956; Müller, 1975; Lenz et al., 1976) and in a number of other fungi (Dutton \& Evans, 1996), as well as in some Streptomyces species (Houck \& Inamine, 1987), the current evidence favours production of oxalic acid by a $\mathrm{Mn}^{2+}$-dependent enzyme, oxaloacetate acetylhydrolase (EC 3.7.1.1) $(\mathrm{OAH})$. In A. niger this enzyme is localized in the cytoplasm (Kubicek et al., 1988), where it catalyses the following reaction:

oxaloacetate $+\mathrm{H}_{2} \mathrm{O} \rightarrow$ oxalate + acetate

Cleland \& Johnson (1956) postulated that a second pathway should exist in A. niger which generates oxalate from pentoses via glycolate and glyoxylate as intermediates. This route requires operation of glyoxylate dehydrogenase as the final step to oxidize glyoxylate to oxalate, but attempts to measure glyoxylate-oxidizing enzymes in extracts of $A$. niger that produced oxalate were unsuccessful (Müller, 1975).

The physiology of oxalic acid production has been studied to some extent (Kubicek, 1987), but some details are lacking, e.g. a proper investigation of the effect of $\mathrm{pH}$ has not been performed. Production of oxalate has been reported to be optimal in the $\mathrm{pH}$ range of 5-8 (Cleland \& Johnson, 1956; Lenz et al., 1976; Kubicek et al., 1988). In most cases information about oxalate biosynthesis has only been obtained under conditions also leading to the synthesis of other organic acids, in particular gluconic acid. In this study we followed another approach using an A. niger mutant lacking glucose oxidase.

In several processes employing $A$. niger, such as citric acid production or production of enzymes, oxalate may arise as an unwanted by-product for a number of reasons. First, it may decrease yield of the intended product. Another reason is that oxalate complicates recovery of the product because additional steps are required to remove the acid. Since oxalic acid is toxic, its removal is particularly important from products that have applications in food or medicine. In this report we describe a number of features of oxalic acid production by $A$. niger and, in addition, we present data on an $A$. niger mutant that is unable to produce oxalic acid and demonstrate its use in citric acid production.

\section{METHODS}

A. niger strains, isolation of mutants, linkage analysis and transformation of $\boldsymbol{A}$. niger. All strains used were descendants from A. niger N400 (CBS 120.49). N573 (cspA1 bioA1) and NW228 (cspA1 bioA1 prtF28) have been described (Van den Hombergh et al., 1995). NW136 (fwnA1 argH12 pyrA6 cspA1 lys A7 hisC3 pheA1 pdxA2 nicB2 trpB2) (Van den Hombergh et al., 1995) was used as a tester strain in genetic analysis. NW253 (cspA1 bioA1 acuA3) and NW254 (cspA1 bioA1 $a c u A 5)$ are two acetate non-utilizing mutants derived from N573 (see Results). NW255 (cspA1 fwnA1 pyrA6 lys A7 acuA5) is a recombinant obtained from a cross between NW254 and NW136. NW131 (cspA1 goxC17) has been described before (Ruijter et al., 1997). NW185 (cspA1 fwnA1 goxC17 prtF28) was constructed in this study and contains the goxC17 (glucose-oxidase-negative) and the prtF28 (oxalate-non-producing) mutations. Acetate-non-utilizing mutants $(a c u)$ were isolated on medium containing propionate as described by Sealy-Lewis (1994). Conidiospores $\left(10^{6}\right)$ of strain N573 were irradiated with UV (60\% survival) and plated on minimal medium (see below) containing $1 \%(\mathrm{w} / \mathrm{v})$ glucose and $0.5 \%$ $(\mathrm{w} / \mathrm{v})$ sodium propionate. Initially 100 colonies were picked and tested for growth on acetate. Linkage analysis was performed as described by Bos et al. (1988). Co-transformation of $A$. niger was performed essentially as described by Kustersvan Someren et al. (1991), using the pyrA gene (Goosen et al., 1987) as a selective marker. Plasmid pRAS7, which contains the Aspergillus nidulans facA gene, encoding acetyl-CoA synthase (ACS) (Sandeman \& Hynes, 1989), was obtained from the Fungal Genetics Stock Center.

Media and culture conditions. Conidiospores were propagated on complete medium (Pontecorvo et al., 1953) solidified with $1.5 \%$ (w/v) agar and containing $50 \mathrm{mM}$ glucose. Spores were harvested from the agar slopes with $0.05 \%(\mathrm{w} / \mathrm{v})$ Tween 80. Cultures were inoculated with spores to a final concentration of $10^{6} \mathrm{ml}^{-1}$. For isolation and analysis of acu mutants mycelium was cultured on minimal medium (MM) (Pontecorvo et al., 1953) containing 0.02\% (v/v) of a trace metal solution (Vishniac \& Santer, 1957) and appropriate carbon sources. For plate tests MM was solidified with $1.5 \%$ $(\mathrm{w} / \mathrm{v})$ agar. Production of acids was studied in 3 litre jacketed stirred tank reactors (Applikon) using two different media. PM medium contained, per litre: $1.2 \mathrm{~g} \mathrm{NaNO}_{3}, 0.5 \mathrm{~g} \mathrm{KH}_{2} \mathrm{PO}_{4}$, $0.2 \mathrm{~g} \mathrm{MgSO}_{4} .7 \mathrm{H}_{2} \mathrm{O}, 0.5 \mathrm{~g}$ yeast extract, $0.04 \mathrm{ml}$ of a trace metal solution (Vishniac \& Santer, 1957) and carbon source as indicated in the legends of tables and figures. Unless indicated otherwise the culture $\mathrm{pH}$ was 5 . Culture $\mathrm{pH}$ was controlled by automatic addition of either $2 \mathrm{M} \mathrm{HCl}$ or $5 \mathrm{M} \mathrm{NaOH}$. Cultures were sparged with 0.2 v.v.m. air, while addition of pure oxygen was used to keep the dissolved oxygen tension above $30 \%$ air saturation. A medium optimized for citric acid production (CAF) was described earlier (Ruijter et al., 1997). In bioreactor cultures $0.5 \mathrm{ml} 30 \%$ polypropylene glycol in alcohol was added per litre of medium as antifoam. Where necessary media were supplemented with, per litre, $4 \mu \mathrm{g}$ biotin, $0.2 \mathrm{~g}$ arginine, $0.2 \mathrm{~g}$ phenylalanine, $0.1 \mathrm{mg}$ pyridoxine, $1 \mathrm{mg}$ nicotinamide, $0.2 \mathrm{~g}$ tryptophan, $0.2 \mathrm{~g}$ histidine, $0.365 \mathrm{~g}$ lysine and $1.22 \mathrm{~g}$ uridine. In all experiments $A$. niger was cultured at $30{ }^{\circ} \mathrm{C}$.

Preparation of cell extracts and enzyme assays. Mycelium was collected from a culture sample by filtration under vacuum, washed three times with approximately $50 \mathrm{ml} 10 \mathrm{mM}$ potassium phosphate buffer $\mathrm{pH} 7 \cdot 0$ and frozen in liquid nitrogen. For each sample approximately $0.5 \mathrm{~g}$ of the frozen mycelium was powdered using a micro-dismembrator (B. Braun Biotech) and suspended in $1 \mathrm{ml}$ extraction buffer at $0{ }^{\circ} \mathrm{C}$. For ACS, extraction was done in $100 \mathrm{mM}$ potassium phosphate $\mathrm{pH} 7$ containing $1 \mathrm{mM}$ EDTA, whereas OAH was extracted in $50 \mathrm{mM}$ potassium phosphate $\mathrm{pH} 7$ containing 0.5 mMEDTA, $5 \mathrm{mM}$ 2-mercaptoethanol, $5 \mathrm{mM} \mathrm{MgCl}_{2}, 10 \%$ (v/v) glycerol. Following centrifugation at $15000 \mathrm{~g}$ for $5 \mathrm{~min}$ enzyme activities were assayed in the resulting supernatant. Enzyme assays were performed at $30{ }^{\circ} \mathrm{C}$ using a Shimadzu UV2501 spectrophotometer. Biochemicals were from Boehringer or Sigma. ACS activity was assayed in $75 \mathrm{mM}$ triethanolamine $\mathrm{pH} 8.4$ containing $7.5 \mathrm{mM} \mathrm{MgCl}_{2}, 20 \mathrm{mM}$ malate, $0.4 \mathrm{mM} \mathrm{NAD}{ }^{+}, 2.5 \mathrm{mM}$ ATP, $0.17 \mathrm{mM}$ CoA, $1 \mathrm{U}$ citrate synthase $\mathrm{ml}^{-1}, 100 \mathrm{U}$ malate dehydrogenase $\mathrm{ml}^{-1}$, $20 \mathrm{mM}$ acetate. OAH activity was measured using direct optical determination of oxaloacetate at $255 \mathrm{~nm}$ as described by Lenz et al. (1976). 
Purification of OAH. OAH was purified from strain NW131 cultured for $28 \mathrm{~h}$ on PM medium (see above) containing $2 \%$ $(\mathrm{w} / \mathrm{v})$ glucose at $\mathrm{pH} 6$. Harvest and disruption of mycelium was done as described under 'Preparation of cell extracts and enzyme assays'. Powdered mycelium $(8 \mathrm{~g})$ was suspended in

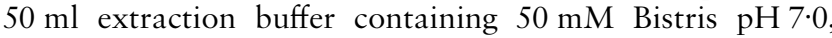
$5 \mathrm{mM} \mathrm{MgCl}_{2}, 0.5 \mathrm{mM}$ EDTA, $5 \mathrm{mM}$ 2-mercaptoethanol and $10 \%(\mathrm{v} / \mathrm{v})$ glycerol. The resulting suspension was centrifuged at $10000 \mathrm{~g}$ for $10 \mathrm{~min}$ at $4{ }^{\circ} \mathrm{C}$. To the supernatant, $\left(\mathrm{NH}_{4}\right)_{2} \mathrm{SO}_{4}$ was added to $40 \%$ saturation. Precipitation of protein was allowed to occur for $20 \mathrm{~min}$ at $4{ }^{\circ} \mathrm{C}$ with gentle mixing. To the supernatant obtained after centrifugation for $10 \mathrm{~min}$ at $10000 \mathrm{~g}$ and $4{ }^{\circ} \mathrm{C},\left(\mathrm{NH}_{4}\right)_{2} \mathrm{SO}_{4}$ was added to obtain $50 \%$ saturation. Following $20 \mathrm{~min}$ incubation at $4{ }^{\circ} \mathrm{C}$ and another centrifugation step the precipitated protein, which contained $\mathrm{OAH}$, was dissolved in $3 \mathrm{ml}$ extraction buffer and applied to a Sephacryl S-300 (Pharmacia Biotech) column $\left(90 \mathrm{~cm} \times 5 \mathrm{~cm}^{2}\right)$ which was pre-equilibrated with extraction buffer. Fractions containing $\mathrm{OAH}$ activity were pooled and applied to a $1 \mathrm{ml}$ Resource Q (Pharmacia Biotech) column. Following rinsing of the column with extraction buffer, adsorbed protein was eluted with a $0-0.5 \mathrm{M} \mathrm{NaCl}$ gradient in extraction buffer over 20 column volumes. Fractions containing $\mathrm{OAH}$ activity were pooled and rechromatographed on Resource Q applying a $0-0.5 \mathrm{M} \mathrm{NaCl}$ gradient over 40 column volumes. Fractions having $\mathrm{OAH}$ activity were stored at $-70{ }^{\circ} \mathrm{C}$

Analytical methods. Denaturing electrophoresis in $10 \%(\mathrm{w} / \mathrm{v})$ polyacrylamide gels containing $0 \cdot 1 \%(\mathrm{w} / \mathrm{v})$ SDS was performed as described by Laemmli (1970) in a Mini-V system (Life Technologies). Molecular mass markers were phosphorylase $b(92 \cdot 5 \mathrm{kDa})$, BSA $(68 \mathrm{kDa})$, ovalbumin $(45 \mathrm{kDa})$ and carbonic anhydrase $(29 \mathrm{kDa})$. For immunochemical detection, protein was blotted onto nitrocellulose filters and blots were then incubated with specific antisera, followed by staining with alkaline phosphatase labelled goat anti-mouse IgG as described by the manufacturer (Bio-Rad). Antibodies against $A$. niger $\mathrm{OAH}$ were prepared as described previously (Van der Veen et al., 1991). Sugars and organic acids were analysed by HPLC using an Aminex HPX-87H (Bio-Rad) column eluted with $25 \mathrm{mM} \mathrm{HCl}$ at $50{ }^{\circ} \mathrm{C}$ and using UV $(210 \mathrm{~nm})$ and RI (refractive index) detection. Sugars and citric acid were, in addition, determined enzymically according to Bergmeyer (1985). Fungal dry weight and protein were determined as described earlier (Ruijter et al., 1997).

\section{RESULTS}

\section{Physiology of oxalic acid production by $A$. niger}

To study production of oxalic acid, an A. niger N400 derivative lacking glucose oxidase (goxC), strain NW131, was used to prevent interference by gluconic acid production. At $\mathrm{pH} 6$ in a minimal medium containing $14 \mathrm{mM} \mathrm{NaNO}$ as the nitrogen source, oxalic acid was produced on all carbon sources tested, including D-glucose, D-fructose, sucrose, D-gluconate, Dxylose, acetate and glycerol. Molar yield [mol $\mathrm{C}$ (oxalate) per mol $\mathrm{C}$ (carbon source)] was in all cases $0 \cdot 5-0 \cdot 6$.

In basidiomycetes, the type and concentration of nitrogen source is known to affect oxalate production (e.g. Micales, 1994; Kuan \& Tien, 1993). Using 2\% glucose as a carbon source, an increase in the $\mathrm{NaNO}_{3}$ concentration from 6 to $60 \mathrm{mM}$ resulted in an increase of

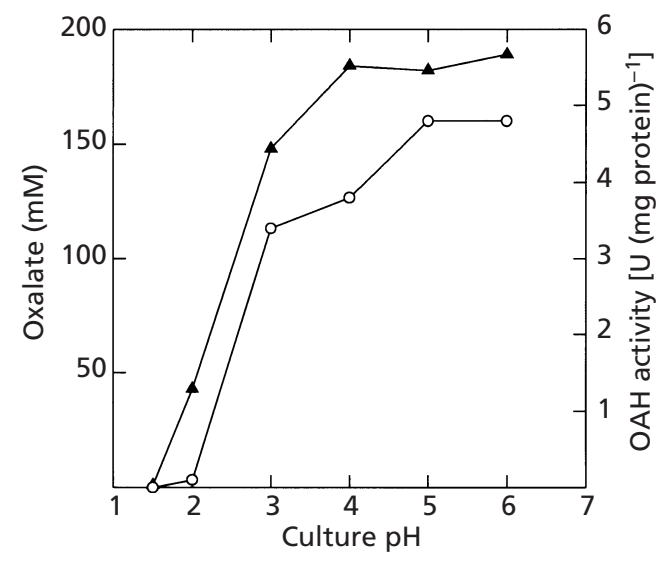

Fig. 1. Oxalate production and $\mathrm{OAH}$ activity as a function of culture $\mathrm{pH}$. A. niger NW131 was cultured for $71 \mathrm{~h}$ on PM medium containing $2 \%(\mathrm{w} / \mathrm{v})$ glucose at the $\mathrm{pH}$ values indicated on the $x$-axis. Since $A$. niger conidiospores did not germinate in $\mathrm{PM}$ medium at $\mathrm{pH} 1.5$, the mycelium was pregrown for $15 \mathrm{~h}$ at $\mathrm{pH} 2$ and the $\mathrm{pH}$ was then adjusted from 2 to 1.5. The final level of oxalate in the cultures is shown $(\boldsymbol{\Delta})$, whereas the $\mathrm{OAH}$ activity in cell extracts $(O)$ was determined after $24 \mathrm{~h}$ of culturing. Data are means of two experiments.

molar yield from 0.5 to 0.54 , with a concomitant increase in dry weight from $3 \cdot 2$ to $4 \cdot 2 \mathrm{~g} \mathrm{l}^{-1}$. Using $28 \mathrm{mM}$ of $\mathrm{NH}_{4} \mathrm{Cl}$ instead of $\mathrm{NaNO}_{3}$ the molar yield was 0.5 (dry weight $5 \cdot 5 \mathrm{~g} \mathrm{l}^{-1}$ ). Thus, the type and concentration of the nitrogen source did not affect the molar yield of oxalic acid very much. These data are in accordance with the findings of Müller (1965), who reported production of $4 \cdot 3-6 \cdot 3 \mathrm{~g}$ oxalate $1^{-1}$ from $50 \mathrm{~g}$ glucose $1^{-1}$ in buffered medium when the $\mathrm{KNO}_{3}$ content was varied between 12 and $100 \mathrm{mM}$.

The environmental factor that influenced production of oxalic acid most was $\mathrm{pH}$ (Fig. 1). Using gox $\mathrm{C}$ strain NW131 oxalic acid production was similar between $\mathrm{pH}$ 4 and 6 (approx. $190 \mathrm{mM}$ oxalate from $110 \mathrm{mM}$ glucose). Below pH 4 the amount of oxalic acid produced decreased. At $\mathrm{pH} 2,40-50 \mathrm{mM}$ was still being produced from $110 \mathrm{mM}$ glucose, but at $\mathrm{pH} 1.5$ oxalic acid production was very low $(<1 \mathrm{mM})$. Production of oxalic acid correlated qualitatively to the $\mathrm{OAH}$ activity measured in cell extracts (Fig. 1). At culture $\mathrm{pH} 3-6$ the $\mathrm{OAH}$ activity was $3 \cdot 5-5 \mathrm{U} \mathrm{mg}^{-1}$, whereas below $\mathrm{pH} 3$ the activity decreased markedly. At culture $\mathrm{pH} 1.5 \mathrm{OAH}$ activity was not detectable.

\section{Properties of OAH}

Our data corroborate published reports that $\mathrm{OAH}$ is responsible for oxalic acid formation in A. niger. We found that the enzyme was present as long as the culture $\mathrm{pH}$ was $\geqslant 3$, but some studies have found a somewhat different regulation of OAH biosynthesis by $\mathrm{pH}$. Kubicek et al. (1988) reported that OAH is not produced at or below pH 4 in A. niger strain B60, and Lenz et al. (1976) described that biosynthesis of OAH in A. niger strain ATCC 1015 is only induced upon a $\mathrm{pH}$ shift from 
Table 1. Purification of $A$. niger $\mathrm{OAH}$

OAH was purified as described in Methods. Data from a representative purification are given.

\begin{tabular}{|lccccc|}
\hline Step & $\begin{array}{c}\text { Volume } \\
(\mathbf{m l})\end{array}$ & $\begin{array}{c}\text { Protein } \\
(\mathbf{m g})\end{array}$ & $\begin{array}{c}\text { Total } \\
\text { activity } \\
(\mathbf{U})\end{array}$ & $\begin{array}{l}\text { Specific } \\
\text { activity } \\
\left(\mathbf{U ~ m g}^{-1}\right)\end{array}$ & $\begin{array}{c}\text { Recovery } \\
(\%)\end{array}$ \\
\hline Extract & 60 & 210 & 903 & $4 \cdot 3$ & 100 \\
$\left(\mathrm{NH}_{4}\right)_{2} \mathrm{SO}_{4} 50 \%$ saturation & $3 \cdot 4$ & 32 & 593 & 19 & 66 \\
Sephacryl S-300 & 58 & $5 \cdot 6$ & 215 & 38 & 24 \\
Resource Q & 5 & $1 \cdot 1$ & 64 & 58 & 7 \\
\hline
\end{tabular}

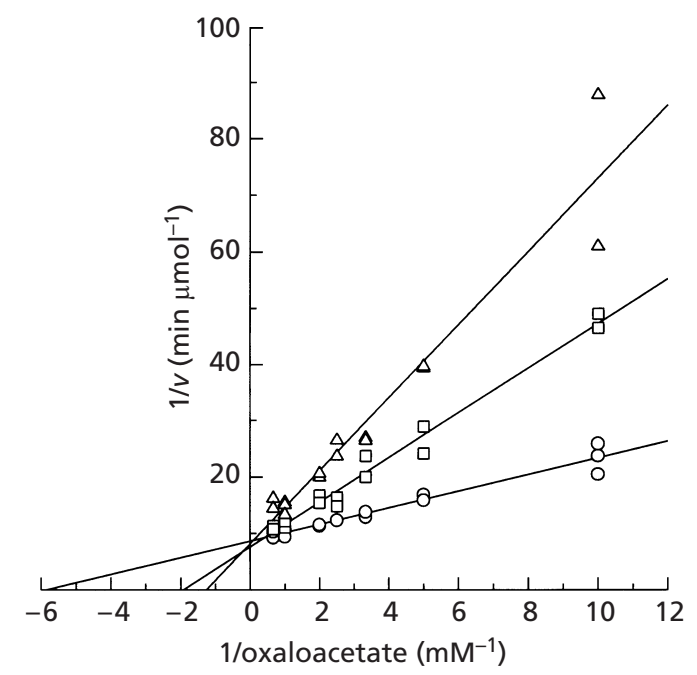

Fig. 2. Inhibition of $\mathrm{OAH}$ activity by oxalate. A doublereciprocal plot of $\mathrm{OAH}$ activity versus the concentration of oxaloacetate is shown at the following concentrations of oxalate: no oxalate $(\bigcirc), 0.05 \mathrm{mM}(\square)$ and $0.1 \mathrm{mM}(\triangle)$. Assay conditions are described in Methods. In all assays $0.1 \mathrm{U} \mathrm{OAH}$ was used.

6 to 8 with $\mathrm{Na}_{2} \mathrm{CO}_{3}$ and not with $\mathrm{NaOH}$. Some enzymic and physico-chemical properties of OAH from A. niger ATCC 1015 have been described in the past (Lenz et al., 1976), but to rule out strain differences and to establish the properties of $A$. niger $\mathrm{N} 400 \mathrm{OAH}$ we purified the enzyme. In three steps we obtained a partially purified enzyme (Table 1). SDS-PAGE of the final Resource Q preparation showed three protein bands of molecular mass $29-33 \mathrm{kDa}$ (data not shown). Since the enzyme could not be further purified by a number of different techniques (including phenyl-Sepharose and chromatofocusing) we decided to characterize the partially purified enzyme. Gel filtration chromatography showed a molecular mass of approximately $250 \mathrm{kDa}$, suggesting that the native enzyme is a multimeric protein. Lenz et al. (1976) reported a molecular mass of $420 \mathrm{kDa}$, which is somewhat larger than the value we determined, but also indicates that the enzyme is a rather large complex. At present, it cannot be ruled out that the complex contains more than one type of subunit. Oxaloacetate was converted to equimolar concentrations of oxalate and acetate by OAH. OAH was dependent on the presence of $\mathrm{Mn}^{2+}$ and maximal activity was obtained at $0.2 \mathrm{mM} \mathrm{MnCl}_{2}$. The activity did not vary much between pH 5.5 and 9 in MES, PIPES, Tris and triethanolamine, but increased approximately twofold when the $\mathrm{pH}$ was increased from 6.5 to $7 \cdot 5$ in imidazole buffer. Optimal activity was obtained in imidazole buffer at $\mathrm{pH} 7 \cdot 6$, which was used in all other experiments. A $K_{\mathrm{m}}$ of $0.17 \mathrm{mM}$ was found for oxaloacetate. Oxalate competitively inhibited hydrolysis of oxaloacetate by $\mathrm{OAH}$ (Fig. 2) with a $K_{\mathrm{i}}$ of $0.03 \mathrm{mM}$, whereas acetate $(100 \mathrm{mM})$ did not inhibit hydrolytic activity of OAH. Thus, although regulation of $\mathrm{OAH}$ biosynthesis by extracellular $\mathrm{pH}$ seems to be different in A. niger strains ATCC 1015 and NW131, the enzymic and physicochemical properties of $\mathrm{OAH}$ from these strains are similar.

\section{Acid production by an ACS (acuA) mutant}

A striking observation during oxalate production is that acetate is never detected in the culture broth. If $\mathrm{OAH}$ is the only enzyme involved in oxalate production, the acetate formed must be very efficiently reconsumed. To investigate acetate consumption by $A$. niger we isolated acetate-non-utilizing $(a c u)$ mutants. Following UV mutagenesis we selected colonies that were resistant to propionate on minimal medium plates containing glucose as the carbon source. Four of these propionateresistant mutants grew less well than the parental strain on acetate medium and belonged to two different complementation groups. The acuA5 mutation was localized on chromosome VI by linkage analysis. One other mutant was also $a c u A$, whereas the two remaining mutants belonged to another complementation group, which was designated $a c u B$. The $a c u B$ mutation was localized on chromosome VIII, but not further analysed. When pregrown on glucose and transferred to acetate medium, the acuA mutants lacked ACS activity, whereas the parental strain N573 had an acetate-induced ACS activity of $0.73 \mathrm{U} \mathrm{mg}^{-1}$. When grown on glucose N573 had an ACS activity of $0.36 \mathrm{U} \mathrm{mg}^{-1}$. This shows that ACS is present during growth on sugars and suggests that acetate metabolism is probably not very much repressed by glucose. Co-transformation of the $a c u A$ pyrA strain NW255 with pRAS7, containing the $A$. nidulans facA gene (encoding ACS), and pGW635, 


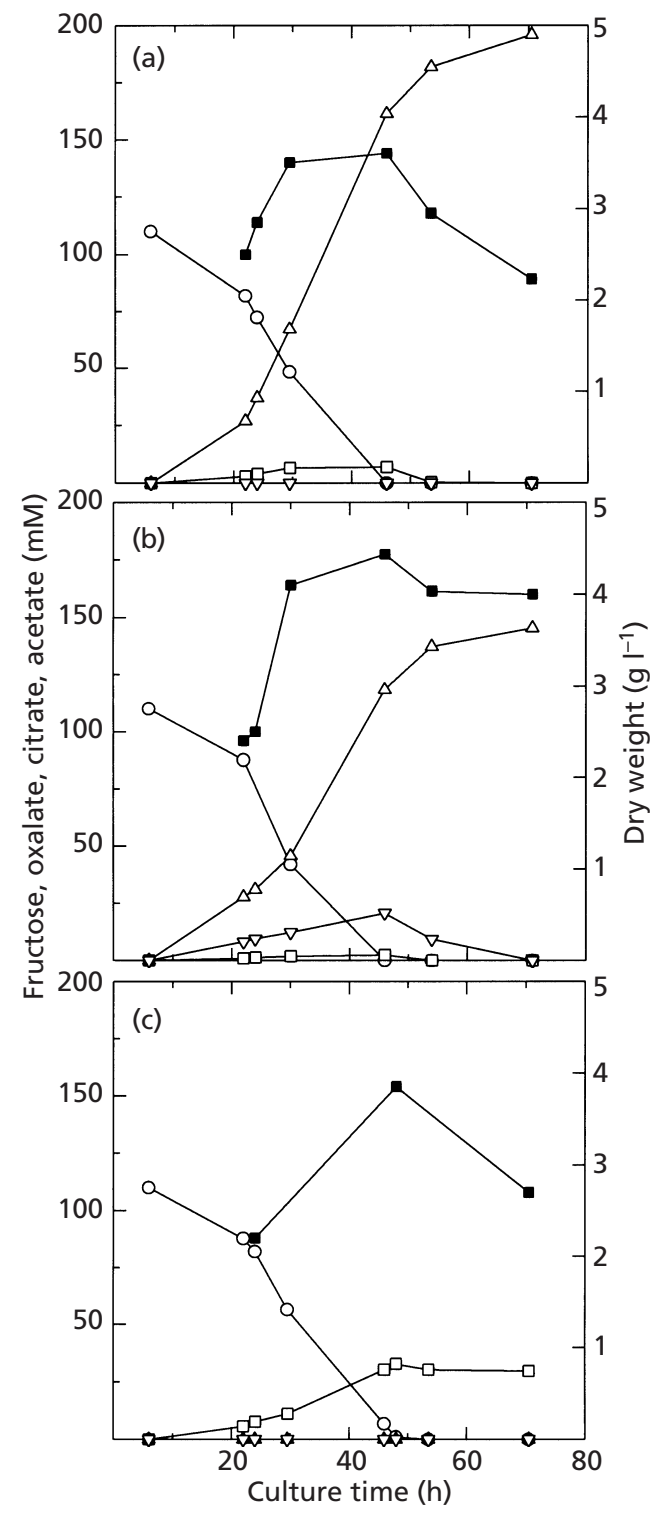

Fig. 3. Acid production by $A$. niger wild-type, an acuA mutant and a prtF mutant. Strains N573 (wild-type, a), NW254 (acuA, b) and NW228 (prtF, c) were cultured on PM containing $2 \%(\mathrm{w} / \mathrm{v})$ fructose at $\mathrm{pH}$. Data are means of two experiments. $\bigcirc$, Fructose; $\mathbf{\square}$, dry weight; $\triangle$, oxalate; $\square$, citrate; $\nabla$, acetate.

containing the $A$. niger pyrA gene, resulted in a number of $p y r A^{+}$transformants. Of five transformants isolated, four were able to grow on acetate, showing that $a c u A$ encodes ACS. These results confirm data of Sealy-Lewis \& Fairhurst (1998), who recently described A. niger acu mutants as well.

Strain N573 did not produce acetate from fructose, whereas approximately $200 \mathrm{mM}$ oxalate is produced (Fig. 3a). In contrast, strain NW254, carrying acuA5, transiently produced acetate (Fig. 3b). During consumption of fructose, acetate slowly accumulated to a maximal concentration of $21 \mathrm{mM}$ in the culture broth, but was reconsumed after exhaustion of the fructose.
The rates of acetate consumption can be calculated from the data. Between 30 and $46 \mathrm{~h}$ of culturing, the acuA5 mutant produced $1.06 \mathrm{mmol}$ oxalate $(\mathrm{g} \text { dry } \mathrm{wt})^{-1} \mathrm{~h}^{-1}$ and $0.12 \mathrm{mmol}$ acetate $(\mathrm{g} \text { dry wt })^{-1} \mathrm{~h}^{-1}$. With $\mathrm{OAH}$ producing equimolar oxalate and acetate, the difference is the acetate consumption by the mutant: $0.94 \mathrm{mmol}(\mathrm{g}$ dry $\mathrm{wt})^{-1} \mathrm{~h}^{-1}$. Between 46 and $54 \mathrm{~h}$ there is net consumption of acetate $\left[0.33 \mathrm{mmol}(\mathrm{g} \text { dry } \mathrm{wt})^{-1} \mathrm{~h}^{-1}\right]$, but still production of oxalate and concomitantly acetate $\left[0.57 \mathrm{mmol}(\mathrm{g} \text { dry } \mathrm{wt})^{-1} \mathrm{~h}^{-1}\right]$. The difference $[0.9 \mathrm{mmol}$ $\left.(\mathrm{g} \text { dry wt })^{-1} \mathrm{~h}^{-1}\right]$ is again the acetate consumption rate, which closely matches the rate calculated for the period 30-46 h. Since ACS activity was not detectable, the remaining acetate catabolism probably proceeds via another pathway, which is unknown at present.

\section{Identification of an oxalate-non-producing mutant}

We previously described a number of $A$. niger mutants that exhibited reduced extracellular protease activity (Van den Hombergh et al., 1995). Upon closer examination of these mutants it was found that one mutation, $\operatorname{prtF28}$, resulted in decreased acidification of the culture broth under certain conditions. Analysis of the culture broth showed that the prtF28 mutant did not produce any oxalate from fructose (Fig. 3c) under conditions that yield about $200 \mathrm{mM}$ oxalate by the parental strain (Fig. $3 a)$. Instead the mutant produced about $35 \mathrm{mM}$ citric acid from $110 \mathrm{mM}$ fructose. The simplest explanation for the absence of oxalate production was a defect in $\mathrm{OAH}$ and indeed this was found. Whereas strain N573 had $4.4 \mathrm{U} \mathrm{mg}^{-1} \mathrm{OAH}$ activity, the prtF28 mutant completely lacked $\mathrm{OAH}$ activity. Using an antiserum raised against partially purified $\mathrm{OAH}$ it was shown by Western blotting analysis that the $\mathrm{OAH}$ protein was absent in the prtF28 mutant, but present in the wild-type (data not shown).

A recombinant strain was constructed that combined the acuA5 and prtF28 mutations. This strain did not produce any acetate from fructose, suggesting that the acetate produced by the acuA5 mutant is associated with oxalate production, i.e. formed by $\mathrm{OAH}$.

\section{Citric acid production by a prtF mutant}

The finding that the prtF28 mutant produced a reasonable amount of citric acid from $2 \%(\mathrm{w} / \mathrm{v})$ fructose at $\mathrm{pH}$ 5 prompted us to investigate citric acid production by this strain. For this purpose a recombinant, NW185, was constructed that lacked both glucose oxidase (goxC17) and $\mathrm{OAH}$ (prtF28). In a traditional citric acid production process (i.e. $\mathrm{pH}<2$, no $\mathrm{Mn}^{2+}$ ) strain NW185 performed comparably to a strain not carrying the $p r t F$ mutation (NW131) using glucose as the substrate (Table 2). However, at $\mathrm{pH} 5$ in a minimal medium containing a mixture of trace metals (PM), NW131 produced a large amount of oxalic acid in addition to citric acid, whereas NW185 produced only citric acid (Table 2 ). The amount of citric acid produced by NW185 in PM at pH 5 is even slightly higher than observed in the traditional citric 
Table 2. Major components of the fermentation broth during acid production on two different media by $A$. niger strains NW131 and NW185

NW131 (goxC17) and NW185 (goxC17 prtF28) were cultured for $4 \mathrm{~d}$ either on a traditional citric acid production medium (CAF) or on a minimal medium containing yeast extract and trace metals (PM) (for exact composition of the media, see Methods). In all cases the carbon source was $14 \%$ $(\mathrm{w} / \mathrm{v})$ glucose. Data are means $( \pm \mathrm{SD})$ and are given in $\mathrm{g}^{-1}$. The numbers in parentheses are the number of independent fermentations for which the components were determined.

\begin{tabular}{|lcccc|}
\hline & CAF NW131 & CAF NW185 & PM NW131 & PM NW185 \\
\hline Glucose & $83 \cdot 5 \pm 4 \cdot 5(10)$ & $84 \cdot 6 \pm 0 \cdot 6(3)$ & $66 \cdot 4 \pm 0 \cdot 3(2)$ & $74 \cdot 6 \pm 2 \cdot 1(2)$ \\
Dry weight & $11 \cdot 2 \pm 1 \cdot 0(10)$ & $11 \cdot 2 \pm 0 \cdot 1(3)$ & $6 \cdot 1 \pm 0 \cdot 3(2)$ & $10 \cdot 9 \pm 0 \cdot 8(2)$ \\
Citric acid & $30 \cdot 7 \pm 1 \cdot 5(10)$ & $28 \cdot 4 \pm 0 \cdot 7(3)$ & $18 \cdot 4 \pm 2 \cdot 0(2)$ & $32 \cdot 6 \pm 0 \cdot 4(2)$ \\
Oxalic acid & $0 \cdot 0$ & $0 \cdot 0$ & $34 \cdot 0 \pm 0 \cdot 7(2)$ & $0 \cdot 0$ \\
\hline
\end{tabular}

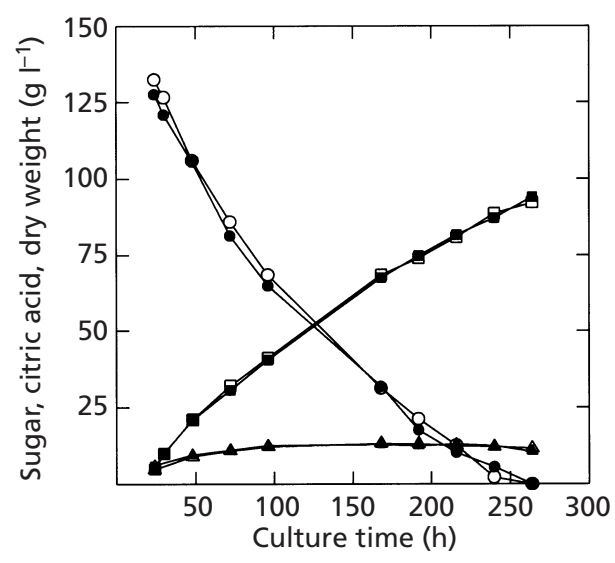

Fig. 4. Citric acid production by $A$. niger goxC prtF mutant NW185 at pH 5 and in the presence of manganese. NW185 was cultured in PM medium containing $14 \%(\mathrm{w} / \mathrm{v})$ sucrose at $\mathrm{pH} 5$ in the absence (open symbols) and presence (filled symbols) of $50 \mu \mathrm{M} \mathrm{MnCl}$. Data are means of two experiments. $\bigcirc$, Sugar (sucrose + glucose + fructose), $\square, \boldsymbol{\square}$, citric acid; $\triangle, \boldsymbol{\Delta}$, dry weight.

acid fermentation. We tested a number of different conditions (e.g. using glucose, fructose or sucrose as the substrate, regulation of $\mathrm{pH}$ at 5 or no $\mathrm{pH}$ regulation) and found that production was optimal from sucrose at $\mathrm{pH}$ 5. Under these conditions NW185 produced approximately $90 \mathrm{~g}$ citric acid from $140 \mathrm{~g}$ sucrose in $10 \mathrm{~d}$ (Fig. 4). PM contains $1 \mu \mathrm{M} \mathrm{Mn}^{2+}$ (55 p.p.b.), which is well above the concentration recommended in citric acid fermentation (<1 p.p.b.; Mattey, 1992). To test whether NW185 was sensitive to $\mathrm{Mn}^{2+}$ we again performed fermentation in $\mathrm{PM}$ at $\mathrm{pH} 5$ using sucrose, but $50 \mu \mathrm{M}$ $\mathrm{MnCl}_{2}$ (2.7 p.p.m.) was now added. Surprisingly, citric acid production was almost identical to that in the fermentation with $1 \mu \mathrm{M} \mathrm{MnCl}_{2}$ (Fig. 4). Thus, it appears that with the $p r t F$ mutation citric acid can be produced at relatively neutral $\mathrm{pH}$ and production is then completely insensitive to the presence of $\mathrm{Mn}^{2+}$. Like a goxC strain, a goxC prtF strain does not produce any citric acid in a traditional citric acid fermentation medium to which $50 \mu \mathrm{M} \mathrm{MnCl}_{2}$ was added (data not shown). This implies that the requirement for $\mathrm{Mn}^{2+}$ deficiency is related to the specific conditions in a traditional citric acid fermentation and not to the $p r t F$ mutation. Only at relatively neutral $\mathrm{pH}$ is the absence or presence of $\mathrm{Mn}^{2+}$ no longer relevant.

\section{DISCUSSION}

Most of the data available on oxalic acid production by A. niger are in favour of $\mathrm{OAH}$ being the only enzyme responsible for oxalate production. (1) Label distribution patterns in experiments using ${ }^{14} \mathrm{CO}_{2}$ showed that oxalate probably originates from hydrolysis of oxaloacetate (Kubicek et al., 1988). In earlier experiments, using a number of ${ }^{14} \mathrm{C}$-labelled carbon sources, Cleland \& Johnson (1956) concluded, also on the basis of product labelling, that for most carbon sources oxalate was produced via oxidation of glyoxylate or glycolate. However, as already mentioned by Kubicek et al. (1988), Cleland \& Johnson (1956) used long labelling times. In these experiments the acetate, produced also by $\mathrm{OAH}$, is probably reconsumed and also converted to oxalate (see below). This severely complicates interpretation of the labelling data and may explain why these authors concluded that oxalate could not be produced by hydrolysis of oxaloacetate from most of the substrates tested, but should arise via oxidation of glyoxylate. Müller (1975) could not detect any activity of glyoxylateoxidizing enzymes in extracts of A. niger mycelium that produced oxalate, whereas $\mathrm{OAH}$ activity was readily identified. Although the failure to detect any glyoxylateoxidizing activity could be due to unfavourable extraction and/or assay conditions, the results taken together strongly suggest that this pathway is not involved in oxalate formation. (2) Our data show that oxalate production correlates with $\mathrm{OAH}$ activity when the culture $\mathrm{pH}$ is varied. In addition, Kubicek et al. (1988) reported that in a $\mathrm{pH}$-shift experiment OAH biosynthesis correlated with formation of oxalic acid. These data justify the conclusion that $\mathrm{OAH}$ is responsible for oxalate formation and also that production of the acid is controlled by expression of the gene(s) encoding OAH. (3) It has been shown by us and previously also by Lenz et al. (1976) with partially 
purified $\mathrm{OAH}$ that the enzyme produces equimolar amounts of oxalate and acetate. However, wild-type $A$. niger did not produce any acetate. This might be explained by involvement of another enzyme, such as glyoxylate dehydrogenase, exclusively leading to oxalate production. We have shown here that some acetate is transiently produced by an acuA mutant, which lacks ACS. After depletion of fructose the acetate formed is slowly consumed again, indicating that some acetate catabolism was still possible by the acuA mutant. These results suggest that wild-type $A$. niger is able to catabolize acetate sufficiently fast to prevent its production and explains why acetate is never observed during oxalate production. (4) With the properties of the prtF28 mutant we now present strong evidence that $\mathrm{OAH}$ is the only enzyme involved in oxalate production in A. niger. The prtF28 mutant lacks OAH activity and does not produce oxalate. It can be argued that $\operatorname{prtF}$ is a mutation that has broader effects than merely the absence of $\mathrm{OAH}$, for instance it may also result in absence of other enzymes potentially involved in oxalate production, but the simplest explanation is a mutation in the gene encoding OAH. prtF was originally described as a mutation that decreased extracellular protease activity (Van den Hombergh et al., 1995). None of the biochemical defects of the prt mutations was known at that point, but the prtF mutation now appears to cause a defect in $\mathrm{OAH}$. Because the strain does not produce oxalic acid, the reduced acidification of the environment probably leads to lower induction of extracellular proteases expressed under acidic conditions.

In traditional citric acid production processes two very important conditions to obtain a good fermentation are low $\mathrm{pH}(<2)$ and absence of $\mathrm{Mn}^{2+}$. Low $\mathrm{pH}$ is important mainly to prevent production of gluconic acid and oxalic acid. A low starting $\mathrm{pH}$ of the medium might easily be obtained with relatively clean substrates, such as glucose syrups, but is more difficult to achieve in crude media, such as molasses, which have a high buffering capacity at $\mathrm{pH} 5-6$. A mutant lacking both glucose oxidase $($ gox $C)$ and $\mathrm{OAH}(p r t F)$ produced citric acid at relatively neutral $\mathrm{pH}$ and could therefore be particularly advantageous in production processes making use of molasses. An additional advantage is that it is no longer necessary to remove metal ions by, for example, potassium ferrocyanide treatment or cationexchange treatment of the substrate, because, in the media tested, the mutant is completely insensitive to the presence of $\mathrm{Mn}^{2+}$. Although we have shown here the usefulness of an oxalate non-producing strain for citric acid production, it is clear that such a strain will also be valuable in other processes employing $A$. niger, such as production of enzymes. In particular, downstream processing may be simplified when oxalate is no longer produced. Besides applying mutagenesis and selection of oxalate-negative mutants, it is obvious that cloning of the oab gene and subsequent gene disruption provides a straightforward approach to eliminate oxalate production.

The main conclusions from the work described in this paper are: (1) The external $\mathrm{pH}$ was the main factor controlling oxalic acid production by A. niger. (2) An oxalate non-producing $A$. niger mutant lacked $\mathrm{OAH}$, implying that $\mathrm{OAH}$ is the only enzyme involved in oxalate production in A. niger. (3) A strain lacking both glucose oxidase $(g \circ x \mathrm{C})$ and $\mathrm{OAH}(p r t F)$ produced citric acid from sugar substrates in a regular synthetic medium at $\mathrm{pH} 5$ and under these conditions production was completely insensitive to $\mathrm{Mn}^{2+}$.

\section{ACKNOWLEDGEMENTS}

The work described in this paper was financially supported in part by the Ministry of Economic Affairs, the Ministry of Education, Culture and Science, and the Ministry of Agriculture, Nature Management and Fishery in the framework of an industrially relevant research programme of the Netherlands Association of Biotechnology Centres (ABON). The authors would like to thank Eveline Manniën and Koen Pelgrom for performing some of the experiments.

\section{REFERENCES}

Bergmeyer, H. U. (1985). Methods of Enzymatic Analysis, vols VI and VII. Deerfield Beach FL: VCH.

Bos, C. J., Debets, A. J. M., Swart, K., Huybers, A., Kobus, G. \& Slakhorst, S. M. (1988). Genetic analysis and the construction of master strains for assignment of genes to six linkage groups in Aspergillus niger. Curr Genet 14, 437-443.

Cleland, W. W. \& Johnson, M. J. (1956). Studies on the formation of oxalic acid by Aspergillus niger. J Biol Chem 220, 595-606.

Dutton, M. V. \& Evans, C. S. (1996). Oxalate production by fungi: its role in pathogenicity and ecology in the soil environment. Can J Microbiol 42, 881-895.

Goosen, T., Bloemheuvel, G., Gysler, C., de Bie, D. A., Van den Broek, H. W. J. \& Swart, K. (1987). Transformation of Aspergillus niger using the homologous orotidine-5'-phosphatedecarboxylase gene. Curr Genet 11, 499-503.

Hayaishi, O., Shimazono, H., Katagiri, M. \& Saito, Y. (1956). Enzymatic formation of oxalate and acetate from oxaloacetate. J Am Chem Soc 78, 5126-5127.

Houck, D. R. \& Inamine, E. (1987). Oxalic acid biosynthesis and oxaloacetate acetylhydrolase activity in Streptomyces cattleya. Arch Biochem Biophys 259, 58-65.

Kuan, L.-C. \& Tien, M. (1993). Stimulation of Mn peroxidase activity: a possible role for oxalate in lignin degradation. Proc Natl Acad Sci USA 90, 1242-1246.

Kubicek, C. P. (1987). The role of the citric acid cycle in fungal organic acid fermentations. Biochem Soc Symp 54, 113-126.

Kubicek, C. P., Schreferl-Kunar, G., Wöhrer, W. \& Röhr, M. (1988). Evidence for a cytoplasmic pathway of oxalate biosynthesis in Aspergillus niger. Appl Environ Microbiol 54, 633-637.

Kusters-van Someren, M. A., Harmsen, J. A. M., Kester, H. C. M. \& Visser, J. (1991). Structure of the Aspergillus niger pelA gene and its expression in Aspergillus niger and Aspergillus nidulans. Curr Genet 20, 293-299.

Laemmli, U. K. (1970). Cleavage of structural proteins during the assembly of the head of bacteriophage T4. Nature 227, 680-685.

Lenz, H., Wunderwald, P. \& Eggerer H. (1976). Partial purification and some properties of oxalacetase from Aspergillus niger. Eur J Biochem 63, 225-236. 
Mattey, M. (1992). The production of organic acids. CRC Crit Rev Biotechnol 12, 87-132.

Micales, J. A. (1994). Induction of oxalic acid by carbohydrate and nitrogen sources in the brown-rot fungus Postia placenta. Mater Org 28, 197-207.

Müller, H.-M. (1965). Untersuchungen zum Saürestoffwechsel von Aspergillus niger. I. Mitteilung. Der Einfluss des C/NVerhältnisses in der Ausgangs-nährlsung auf den $\mathrm{pH}-$ Wert und die Oxalsaüreanhäufung. Arch Microbiol 52, 251-265.

Müller, H.-M. (1975). Oxalate accumulation from citrate by Aspergillus niger. I. Biosynthesis of oxalate from its ultimate precursor. Arch Microbiol 103, 185-189.

Murphy, R. J. \& Levi, J. F. (1983). Production of copper oxalate by some copper tolerant fungi. Trans Br Mycol Soc 54, 165-168.

Pontecorvo, G., Roper, J. A., Hemmons, L. M., MacDonald, K. D. \& Bufton, A. W. J. (1953). The genetics of Aspergillus nidulans. Adv Genet 5, 141-238.

Ruijter, G. J. G., Panneman, H. \& Visser, J. (1997). Overexpression of phosphofructokinase and pyruvate kinase in citric acid producing Aspergillus niger. Biochim Biophys Acta 1334, 317-326.

Sandeman, R. A. \& Hynes, M. J. (1989). Isolation of the $f a c A$ (acetyl-CoenzymeA synthase) and $a c u E$ (malate synthase) genes from Aspergillus nidulans. Mol Gen Genet 218, 87-92.

Sealy-Lewis, H. M. (1994). A new selection method for isolating mutants defective in acetate utilisation in Aspergillus nidulans. Curr Genet 25, 47-48.

Sealy-Lewis, H. M. \& Fairhurst, V. (1998). Isolation of mutants deficient in acetyl-CoA synthetase and a possible regulator of acetate induction in Aspergillus niger. Microbiology 144, 1895-1900.

Shanta, T. \& Rati, E. R. (1990). Isolation and characterization of an aflatoxin-inhibiting metabolite from Aspergillus niger. Curr Sci 59, 326-327.

Strasser, H., Burgstaller, W. \& Schinner, F. (1994). High-yield production of oxalic acid for metal leaching processes by Aspergillus niger. FEMS Microbiol Lett 119, 365-370.

Tanaka, K. \& Nonaka, F. (1981). Synergistic action of oxalic acid and pectinolytic enzyme on the rot of onion bulb caused by Aspergillus niger. Ann Phytopathol Soc Japan 47, 166-174.

Van de Merbel, N. C., Ruijter, G. J. G., Lingeman, H., Brinkman, U. A. Th. \& Visser, J. (1994). An automated monitoring system using on-line ultrafiltration and column liquid chromatography for Aspergillus niger fermentations. Appl Microbiol Biotechnol 41, 658-663.

Van den Hombergh, J. P. T. W., Van de Vondervoort, P. J. I., Van der Heijden, N. C. B. A. \& Visser, J. (1995). New protease mutants in Aspergillus niger result in strongly reduced in vitro degradation of target proteins; genetic and biochemical characterization of seven complementation groups. Curr Genet 28, 299-308.

Van der Veen, P., Flipphi, M. J. A., Voragen, A. G. J. \& Visser, J. (1991). Induction, purification and characterisation of arabinases produced by Aspergillus niger. Arch Microbiol 157, 23-28.

Vishniac, W. \& Santer, M. (1957). The thiobacilli. Bacteriol Rev 21, 195-213.

Received 1 February 1999; revised 28 April 1999; accepted 10 May 1999. 